\title{
Regulation of Toll-like receptor 1 and -2 in neonatal mice brains after hypoxia-ischemia
}

Linnea Stridh ${ }^{1}$, Peter LP Smith ${ }^{1}$, Andrew S Naylor ${ }^{1,2}$, Xiaoyang Wang ${ }^{1,3}$ and Carina Mallard ${ }^{1 *}$

\begin{abstract}
Background: Hypoxic-ischemic (HI) brain injury remains a major problem in newborns, resulting in increased risk of neurological disorders. Neonatal HI triggers a broad inflammatory reaction in the brain, including activation of the innate immune system. Toll-like receptors (TLRs), which are key components of the innate immune system, are believed to play a role in adult cerebral ischemic injury. The expression of TLRs in the neonatal brain and their regulation after $\mathrm{HI}$ is unknown.
\end{abstract}

Methods: Wild type C57BL/6, TLR 1 knockout (KO) and TLR 2 KO mice were subjected to HI at postnatal day 9 and sacrificed 30 min, 6 h, 24 h or 5 days after HI. TLR mRNA expression was determined by RT-qPCR and protein and cell type localisation by immunohistochemistry (IHC). To evaluate brain injury, infarct volume was measured in the injured hemisphere.

Results: mRNA expression was detected for all investigated TLRs (TLR1-9), both in normal and HI exposed brains. After HI, TLR-1 was down-regulated at $30 \mathrm{~min}$ and up-regulated at $6 \mathrm{~h}$ and $24 \mathrm{~h}$. TLR-2 was up-regulated at $6 \mathrm{~h}$ and $24 \mathrm{~h}$, and TLR-7 at $24 \mathrm{~h}$. Both TLR-5 and TLR-8 were down-regulated at $24 \mathrm{~h}$ and 30 min respectively. IHC showed an increase of TLR-1 in neurons in the ipsilateral hemisphere after HI. TLR-2 was constitutively expressed in astrocytes and in a population of neurons in the paraventricular nucleus in the hypothalamus. No changes in expression were detected following HI. Following HI, TLR-2 KO mice, but not TLR-1 KO, showed a decreased infarct volume compared to wild type ( $p=0.0051)$.

Conclusions: This study demonstrates that TLRs are regulated after $\mathrm{HI}$ in the neonatal brain. TLR-1 protein was upregulated in injured areas of the brain but TLR-1 KO animals were not protected from HI. In contrast, TLR-2 was constitutively expressed in the brain and TLR-2 deficiency reduced HI injury. These data suggest that TLR-2, but not TLR-1, plays a role in neonatal HI brain injury.

\section{Background}

Perinatal brain injury remains a major clinically acute and chronic problem resulting in increased risk of neurological disorders such as cerebral palsy and epilepsy. Although the precise aetiology of brain injury in the newborn is sometimes unclear, hypoxia-ischemia (HI) is well accepted as a contributing factor [1]. Both infection and intrapartum asphyxia is associated with inflammation in the brain [2] and there are increased levels of cytokines in the cerebral spinal fluid in term infants that have suffered birth asphyxia [3]. Experimental studies demonstrate that neonatal HI triggers a broad

\footnotetext{
* Correspondence: carina.mallard@neuro.gu.se

'Institute of Neuroscience and Physiology, Sahlgrenska Academy, University of Gothenburg, Gothenburg, Sweden

Full list of author information is available at the end of the article
}

inflammatory reaction in the brain which includes activation of the innate immune system [4] and several studies in neonatal animals have shown that inhibition of pro-inflammatory mediators are neuroprotective [5-8].

Toll-like receptors (TLRs) are key components of the innate immune system, which recognise a wide variety of pathogen-associated molecular patterns (PAMPs), such as lipopolysaccharide, bacterial DNA, and doublestranded RNA (for reviews see [9-11]). The TLR family consists of 13 members and TLR 1-9 are expressed in both mice and humans. Upon activation, each toll-like receptor, except TLR-3, signals through the myeloid differentiation primary response gene 88 (MyD88)-dependent pathway. MyD88 is an adaptor protein, which upon recruitment to the activated receptor initiates a signalling cascade leading to activation of different
C Biomed Central 
transcription factors, e.g. nuclear factor $\kappa \mathrm{B}(\mathrm{NF} \kappa \mathrm{B})$ and activator protein-1 (AP1). This activation then gives rise to a generation of pro-inflammatory cytokines such as interleukin (IL)- 6 and tumour necrosis factor- $\alpha$ (TNF$\alpha$ ). In contrast, TLR-3 signals through the MyD88-independent pathway, initiated by the Toll/IL-1R domain containing adaptor inducing IFN- $\beta$ (TRIF) molecule. Recruitment of TRIF leads to the activation of the transcription factor interferon regulatory factor (IRF) -3 and -7 and the generation of antiviral molecules such as interferon (IFN)- $\beta$.

In addition to their role in bacterial and viral infections, recent studies have shown that TLRs also recognise and are activated by endogenous molecules associated with damaged cells and tissues [12-14]. For example, Lehnardt et al. demonstrated that the intracellular chaperone heat shock protein 60 released from dying cells in the central nervous system activates microglia through a TLR-4- and MyD88-dependent pathway [13]. In addition, Karikó et al. revealed that RNA released from or associated with necrotic cells stimulated TLR-3 and induced an immune response [12]. Furthermore, growing evidence suggests that TLRs play a role in ischemic brain damage. In adult studies, TLR-4 has been found to be up-regulated after cerebral ischemia reperfusion [15] and mice lacking TLR-2 or TLR-4 are less susceptible to hypoxic/ischemic brain damage [16-19].

Most TLRs are constitutively expressed in the adult brain [20,21]. However, the expression of TLRs in the neonatal brain and how they are regulated after $\mathrm{HI}$ is unknown. Here we examine the expression of TLR 1-9 in the neonatal brain, both in control animals and after HI using a well-established animal model of perinatal brain damage $[6,22]$. Furthermore, we examined the functional role of TLR-1 and TLR-2 after HI.

\section{Methods}

\section{Animals}

C57BL/6 mice were purchased from Charles River (Sulzfeld, Germany). TLR-1 knock out (KO) mice were purchased from Oriental BioService, Inc (Tokyo, Japan) and TLR-2 KO mice (B6.129-Tlr2tm1Kir/J) were bought from the Jackson Laboratory (USA). All KO mice were on the C57BL/ 6 background. Mice were housed in a 12 $\mathrm{h}$ light-dark cycle and bred at Experimental Biomedicine (Gothenburg University, Gothenburg, Sweden) and were provided with a standard laboratory chow diet (B\&K, Solna, Sweden) and drinking water ad libitum. All animal experiments were approved by the Ethical Committee of Gothenburg (No.277-07 and 374-09).

\section{Induction of hypoxia-ischemia in neonatal mice}

At postnatal day (PND) 9, mice were anesthetised with isoflurane $(3.0 \%$ for induction and $1.0-1.5 \%$ for maintenance) in a mixture of nitrous oxide and oxygen (1:1). The left common carotid artery was ligated with prolene sutures (the whole procedure was less than $5 \mathrm{~min}$ ). Mice were returned to the cage and allowed to recover for $1 \mathrm{~h}$ and then placed in an incubator circulated with a humidified gas mixture $(10.00 \pm 0.01 \%$ oxygen in nitrogen) at $36^{\circ} \mathrm{C}$ for $50 \mathrm{~min}$. After hypoxia, the pups were returned to their dam until sacrifice. Control animals received no surgery and were not subjected to HI. Two wild type and one TLR-1 KO mice died during the HI procedure.

\section{Tissue collection and processing}

For mRNA expression analysis, wild type pups were deeply anesthetized and intracardially perfused with saline at $30 \min (\mathrm{n}=5), 6 \mathrm{~h}(\mathrm{n}=5)$ and $24 \mathrm{~h}(\mathrm{n}=5)$ after HI. Brains were rapidly dissected out, divided into ipsi- and contralateral hemispheres, snap frozen and then stored at $-80^{\circ} \mathrm{C}$ until analysis. Brain tissue was homogenised with Qiasol lysis reagent homogeniser (Qiagen, Solna, Sweden) and total RNA was extracted using RNeasy Lipid Tissue Mini Kit (Qiagen, Solna, Sweden) according to the manufacturer's instructions. RNA was measured in a spectrophotometer at 260-nm absorbance.

For immunohistochemical analysis, animals were deeply anesthetised and intracardially perfused with saline and $5 \%$ buffered formaldehyde (Histofix; Histolab, Sweden) at $30 \mathrm{~min}, 6 \mathrm{~h}, 24 \mathrm{~h}$ and 5 days after HI. Brains were rapidly removed and immersion fixed in $5 \%$ formaldehyde for $24 \mathrm{~h}$. Brains were then kept in a $30 \%$ sucrose solution until they were cut or put through dehydration with graded ethanol and xylene and embedded in paraffin. Coronal sectioning $(25 \mu \mathrm{m} / \mathrm{sec}-$ tion) was performed on a sliding microtome (Leica SM2000R, Leica Microsystems, Sweden), and sections were stored in tissue cryoprotectant solution (25\% ethylene glycol, 25\% glycerol and $0.1 \mathrm{M}$ phosphate buffer) at $-20^{\circ} \mathrm{C}$. For detection of infarction volume paraffin embedded tissue was used. Paraffin embedded brains were cut coronally $(10 \mu \mathrm{m} / \mathrm{section})$ on a rotating microtome (Leica RM2165, Leica Microsystems, Sweden).

\section{TLR signalling pathway RT2-PCR-Profiler PCR Array}

cDNA-synthesis was performed by using the $\mathrm{RT}^{2}$ First Strand Kit (SABiosciences, Frederick, MD, USA) following the manufacturer's instructions. The mouse TLR signalling pathway $\mathrm{RT}^{2}$-PCR-Profiler PCR Array (SABiosciences, Frederick, MD, USA) was carried out according to manufacturer's instructions using the LightCycler 480 system (Roche, Bromma, Sweden). The raw data obtained from the Lightcycler 480 software was uploaded into GEarray Analyzer software (SABiosciences, Frederick, MD, USA) for analysis. 


\section{Reverse transcription-quantitative PCR}

To confirm the $\mathrm{RT}^{2}$-PCR-Profiler PCR Array results, TLR-1 and -2 mRNA expressions were determined by reverse transcription-quantitative PCR (RT-qPCR). Superscript RNase $\mathrm{H}$ - reverse transcriptase kit (Invitrogen, CA, USA) random hexamer primers and dNTP (Roche Molecular Biochemicals, IN, USA) were used to synthesise first strand cDNA as previously described [23]. Each PCR $(20 \mu \mathrm{l})$ contained $2 \mu \mathrm{l}$ cDNA diluted 1:8, $10 \mu \mathrm{l}$ Quanti Fast SYBR Green PCR Master Mix (Qiagen, Sweden) and $2 \mu \mathrm{l}$ PCR primer. The following primers were used: TLR-1 QuantiTech Primer Assay (QT00157430), TLR-2 QuantiTech Primer Assay (QT00129752) and Hprt-1 QuantiTech Primer Assay (QT00166768), all from Qiagen, Sweden. The amplification protocol comprised an initial 5 min denaturation at $95^{\circ} \mathrm{C}$, followed by 40 cycles of denaturation for $10 \mathrm{sec}$ at $95^{\circ} \mathrm{C}$ and annealing/extension for $30 \mathrm{sec}$ at $60^{\circ} \mathrm{C}$ on a LightCycler 480 (Roche, Sweden). Melting curve analysis was performed to ensure that only one PCR product was obtained. For quantification and for estimation amplification efficiency, a standard curve was generated using increasing concentrations of cDNA. The amplification transcripts were quantified with the relative standard curve and normalised against the reference gene hypoxanthine guanine phosphoribosyltransferase-1 (Hprt-1).

\section{Immunohistochemistry}

Immunohistochemical staining was performed on freefloating $25 \mu \mathrm{m}$ sections pretreated with $0.6 \% \mathrm{H}_{2} \mathrm{O}_{2}$ in Tris-buffered saline (TBS; $0.15 \mathrm{M} \mathrm{NaCl}$ and $0.1 \mathrm{M}$ Tris$\mathrm{HCl}, \mathrm{pH}$ 7.5) for 30 min to block endogenous peroxidase activity. Nonspecific binding was blocked for 30 min in blocking solution (3\% goat serum and $0.1 \%$ Triton-X 100 in TBS). After rinsing, sections were incubated with primary antibody (TLR-1, IMG-5012, 1:500, TLR-2, IMG-526, 1:100, Imgenex, CA, USA) in blocking solution at $4^{\circ} \mathrm{C}$ for $48 \mathrm{~h}$. The tissue sections were then incubated for $1 \mathrm{~h}$ with biotinylated goat anti-rabbit IgG secondary antibody (1:500, Vector Laboratories, CA, USA) in blocking solution and then rinsed in TBS. Visualisation was performed using Vectastain ABC Elite (Vector Laboratories, CA, USA) with $0.5 \mathrm{mg} / \mathrm{ml} \mathrm{3,} \mathrm{3'-}$ diaminobenzidine (DAB) enhanced with 0,01\% $\mathrm{H}_{2} \mathrm{O}_{2}$ and $0,04 \% \mathrm{NiCl}$ (all from Sigma-Aldrich, Sweden). Sections were analysed on an Olympus BX60 fluorescence microscope equipped with an Olympus DP50 cooled digital camera.

For paraffin sections, antigen recovery was performed by boiling the sections in $10 \mathrm{mM}$ sodium citrate buffer ( $\mathrm{pH}$ 6.0) for $10 \mathrm{~min}$. Nonspecific binding was blocked for $30 \mathrm{~min}$ in blocking solution (1\% horse serum, 3\% bovine serum albumin, $0.1 \% \mathrm{NaN}_{3}$ in phosphate buffered saline (PBS)). Sections were incubated in primary antibody against microtubule-associated protein-2 (MAP-2; clone HM-2, 1:1000; Sigma-Aldrich) at $4^{\circ} \mathrm{C}$ overnight, followed by biotinylated horse anti-mouse secondary anti body (1:250, Vector Laboratories) for $60 \mathrm{~min}$ at room temperature. Visualization was performed using Vectastain ABC Elite with $0.5 \mathrm{mg} / \mathrm{ml} \mathrm{3,3 \_ -}$ diaminobenzidine enhanced with $15 \mathrm{mg} / \mathrm{ml}$ ammonium nickel sulfate, $2 \mathrm{mg} / \mathrm{ml} \beta$-D-glucose, $0.4 \mathrm{mg} / \mathrm{ml}$ ammonium chloride, and $0.01 \mathrm{mg} / \mathrm{ml} \beta$-glucose oxidase (all from Sigma-Aldrich).

To identify the cell type specific localisation of TLRs, multi-immunofluorescence staining was performed. Non-specific binding was blocked for 30 min in blocking solution (3\% donkey serum and $0.1 \%$ Triton-X 100 in TBS). TLR antibodies were then incubated simultaneously with antibodies against specific markers for neurons (NeuN 1:1000, MAB377, or alexa 488 conjugated NeuN 1:1000, MAB377X, Chemicon International, USA, and $\mathrm{HuC} / \mathrm{D}$ 1:500, A21271, Molecular Probes, Netherlands), oligodendrocytes (Olig2 1:1000, AF2418, R\&D systems, UK), microglia (Iba-1 1:1000, ab5076, Abcam, UK), and astrocytes (GFAP 1:1000, PCK-591P, Covance, USA) diluted in blocking solution for $48 \mathrm{~h}$ at $4^{\circ} \mathrm{C}$. Samples stained for $\mathrm{HuC} / \mathrm{D}$ were subjected to sodium citrate antigen retrieval $\left(10 \mathrm{mM} \mathrm{NaCi}, \mathrm{pH} 6\right.$ for $30 \mathrm{~min}$ at $80^{\circ} \mathrm{C}$ ) prior to blocking. Immunoreactivity was visualised via appropriate combinations of the following secondary antibodies: donkey anti-chicken DyLight 549 (1:1000, Jackson ImmunoResearch, USA), donkey anti-mouse Alexa 488, donkey anti rabbit Alexa 594, donkey antigoat Alexa 647, and donkey anti-rabbit Alexa 488 (1:1000, all from Molecular probes, Netherlands). Multichannel confocal images were captured with a Leica TCS SP2 confocal system (Leica, Heidelberg, Germany) with channel settings appropriate to the fluorophores present. Sequentially scanned, grey scale Z-stacks were pseudocolored and processed in ImageJ (version 1.42u; National Institutes of Health, Bethesda, MD, http://rsb. info.nih.gov/ij) before final processing in Adobe Photoshop (version 11.0.2; Adobe Systems Inc., San Jose, CA).

\section{Brain infarct evaluation}

For brain infarct evaluation, coronal paraffin sections throughout the hippocampus were used. Every 40th section was stained for MAP-2 and analyzed under a Nikon Optiphot-2 microscope equipped with an Olympus DP50 cooled digital camera. Images were captured and processed using Micro Image version 4.0 (Olympus). Infarct area was assessed as the MAP-2 negative area in the ipsilateral hemisphere and total infarct volume was calculated according to the Cavalieri Principle using the following formula: $\mathrm{V}=\Sigma \mathrm{A} \times \mathrm{P} \times \mathrm{T}$, where $\mathrm{V}=$ total volume, $\Sigma \mathrm{A}=$ the sum of areas measured, $\mathrm{P}=$ 
the inverse of the sections sampling fraction, and $\mathrm{T}=$ the section thickness.

\section{Data analysis and Statistics}

For normalisation of gene expression on the $\mathrm{RT}^{2}$-PCRProfiler PCR Array, five housekeeping genes, $\beta$-glucuronidase, Hprt-1, heat shock protein $90 \mathrm{kDa}$ alpha, glyceraldehyde-3-phosphate dehydrogenase, and $\beta$-actin, were used. The cycle threshold $\left(C_{T}\right)$ was determined for each sample and normalised to the average $\mathrm{C}_{\mathrm{T}}$ of the five housekeeping genes. A comparative $C_{T}$ method was used to calculate relative gene expression. Data are represented as fold change relative to control. The p-value was calculated using a student's t-test (two-tailed, equal variance).

Brain infarct data were analyzed with one way ANOVA followed by Dunnett's Multiple Comparison Test to compare total infarct volume between genotypes or infarct area at each brain level between groups (WT, TLR-1 KO and TLR-2 KO). Data are presented as mean $\pm \mathrm{SD}$ and significance was set at $\mathrm{p} \leq 0.05$. All statistical analyses were performed using GraphPad Prism 4.0 (GraphPad Software).

\section{Results}

mRNA expression of TLRs in normal brain and after hypoxia-ischemia

mRNA expression was detected for all TLRs present on the array in the PND 9 mouse brain (Table 1). Following HI, TLR-1 mRNA was down-regulated at $30 \mathrm{~min}$ (fold change 0.52, $\mathrm{p}=0.004$ ) then up-regulated at $6 \mathrm{~h}$ (fold change 2.39, $\mathrm{p}=0.00001$ ) and $24 \mathrm{~h}$ (fold change $3.36, \mathrm{p}=0.00001$ ); TLR-2 was up-regulated at $6 \mathrm{~h}$ (fold change 1.63, $\mathrm{p}=0.005$ ) and $24 \mathrm{~h}$ (fold change 2.27, $\mathrm{p}=$ 0.006 ) and TLR-7 was up-regulated at $24 \mathrm{~h}$ (fold change $2.16, p=0.005)$. Solely down regulated gene expression after HI was found with TLR-5 at $24 \mathrm{~h}$ (fold change $0.57, \mathrm{p}=0.004$ ) and TLR- 8 at $30 \mathrm{~min}$ (fold change 0.39, $\mathrm{p}=0.006$ ). TLR-3, $-4,-6$ and -9 mRNA expression did not show any significant changes after $\mathrm{HI}$.

Table 1 Fold change values for TLRs $30 \mathrm{~min}, 6 \mathrm{~h}$ and 24 h after $\mathrm{HI}$

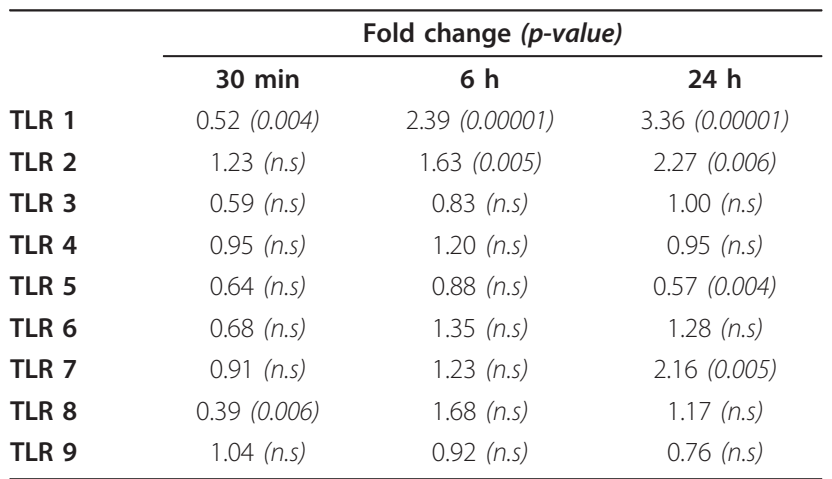

To confirm the RT2-PCR-Profiler PCR Array results, mRNA expression levels for TLR1 and TLR2 were examined using RT-qPCR and normalised against the reference gene Hprt-1. TLR-1 and -2 were selected as they showed both mRNA up-and down-regulation on the array. A similar pattern of mRNA expression was observed for both TLR-1 and -2, when comparing the methods (Figure 1). On the array, TLR-1 showed a fold change of 0.52 at $30 \mathrm{~min}$ and 3.36 at $24 \mathrm{~h}$ after $\mathrm{HI}$. When using RT-qPCR and the TLR-1 expression normalised against Hprt- 1 the fold change was 0.02 at $30 \mathrm{~min}$ and 4.61 at $24 \mathrm{~h}$ (Figure 1A). For TLR-2, the array showed a fold change of 1.23 at $30 \mathrm{~min}$ and 2.27 at $24 \mathrm{~h}$ after HI. RT-qPCR for TLR-2 gave a fold change

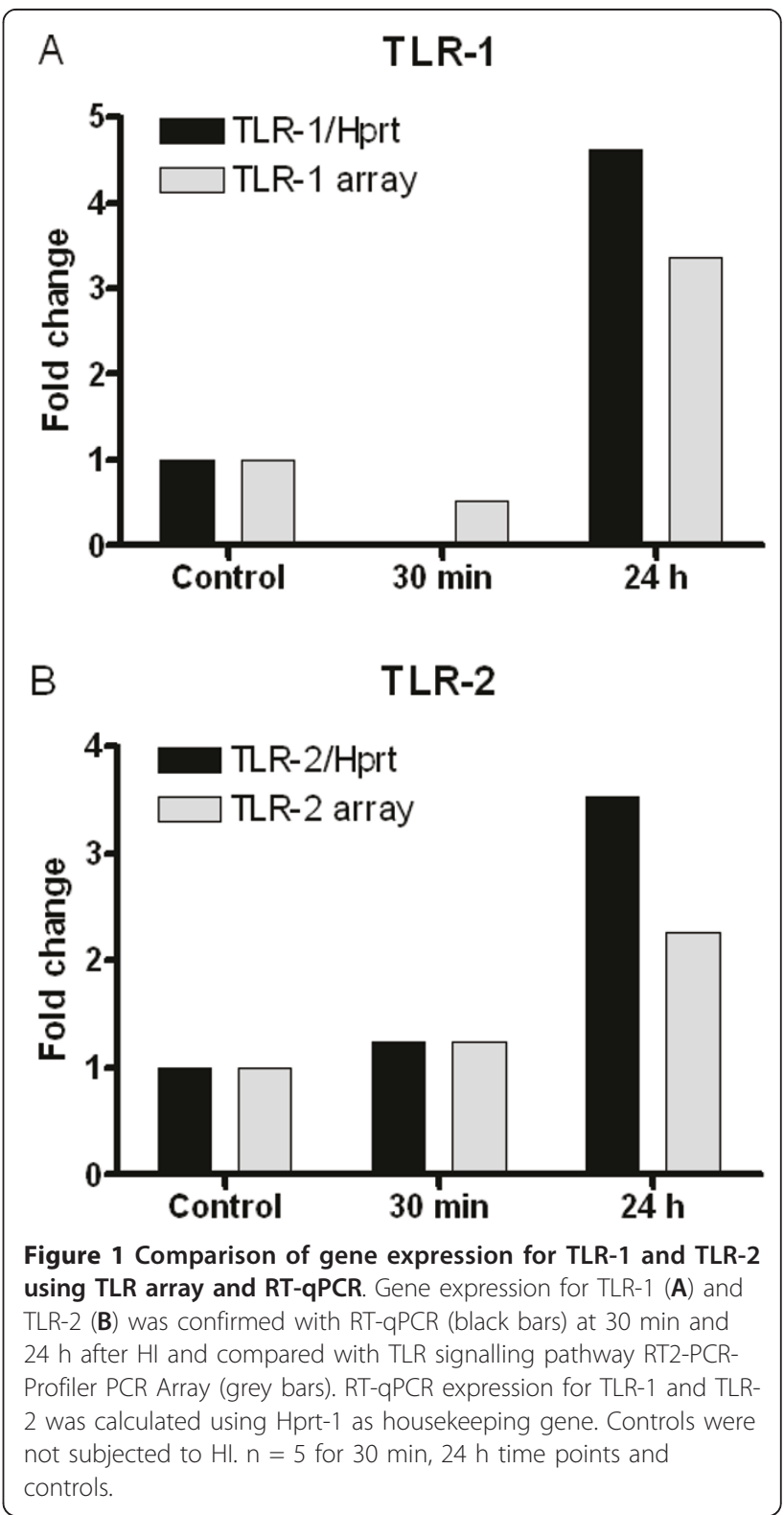


of 1.24 at $30 \mathrm{~min}$ and 3.53 at $24 \mathrm{~h}$ after $\mathrm{HI}$ when normalised against Hprt-1 (Figure 1B).

\section{Protein expression and distribution of TLR-1 and -2 in the brain after hypoxia-ischemia}

To further study TLR regulation following injury, we performed immunohistochemical studies of the TLRs that displayed significant up-regulation of mRNA in response to HI, i.e. for TLR1 and 2. Immunohistochemical experiments performed using an antibody against TLR -7 were unsatisfactory and were not analysed further (data not shown).

No TLR-1 staining was detected in normal control brains or in the contralateral (non-damaged) hemisphere following HI. There was a marked increase of TLR-1 positive cells in the ipsilateral (damaged) hemisphere at $24 \mathrm{~h}$, but not $30 \mathrm{~min}$ and $6 \mathrm{~h}$ after HI. TLR-1 positive staining was mainly observed in the hippocampus (Figure 2A) Double/triple-labelling experiments showed that TLR-1 was expressed in neurons (Figure 3A and 3C) but not in microglia, astrocytes or oligodendrocytes (Figure $3 \mathrm{~A}$ and $3 \mathrm{~B}$ ).

TLR-2-immunoreactivity was observed mainly in the hippocampus, subcortical white matter and stria terminalis (Figure 2B and 2C). Co-staining experiments confirmed that TLR-2 positive cells in white matter areas were astrocytes but not neurons, microglia or oligodendrocytes (Figure 4A-C). A specific population of neuron-like cells expressing TLR-2 was found in the paraventricular nucleus of the hypothalamus (PVN, Figure $2 \mathrm{~B}$ and $2 \mathrm{D}$ ) and was confirmed to be neurons by co-staining experiments (Figure 4D). The immunohistochemical expression of TLR-2 did not change after HI.

\section{Brain infarct in wild type, TLR-1 and -2 KO animals after hypoxia-ischemia}

To further evaluate the role of TLR-1 and TLR-2 in the neonatal brain after HI, we performed studies with TLR-1 and TLR-2 KO mice. Neuropathological analysis at 5 days after $\mathrm{HI}$ showed a significant decrease in infarct volume in TLR-2 KO mice $\left(1.162 \pm 0.791 \mathrm{~mm}^{3}\right.$, $\mathrm{p}=0.005, \mathrm{n}=15)$ compared to WT $(2.528 \pm 1.570$ $\mathrm{mm}^{3}, \mathrm{n}=14$, Figure $\left.5 \mathrm{~A}\right)$. There was no protection in TLR-1 KO mice $\left(2.068 \pm 0.607 \mathrm{~mm}^{3}, \mathrm{n}=13\right)$. The infarct area was significantly decreased in 3 out of 4 levels throughout hippocampus in TLR-2 KO mice compared to WT (Figure 5B). Figure 5C demonstrates representative images of level 3 of the hippocampus for the different genotypes.

\section{Discussion}

We detected mRNA transcripts for all TLRs (TLR1-9) in the normal immature brain and regulation of mRNA

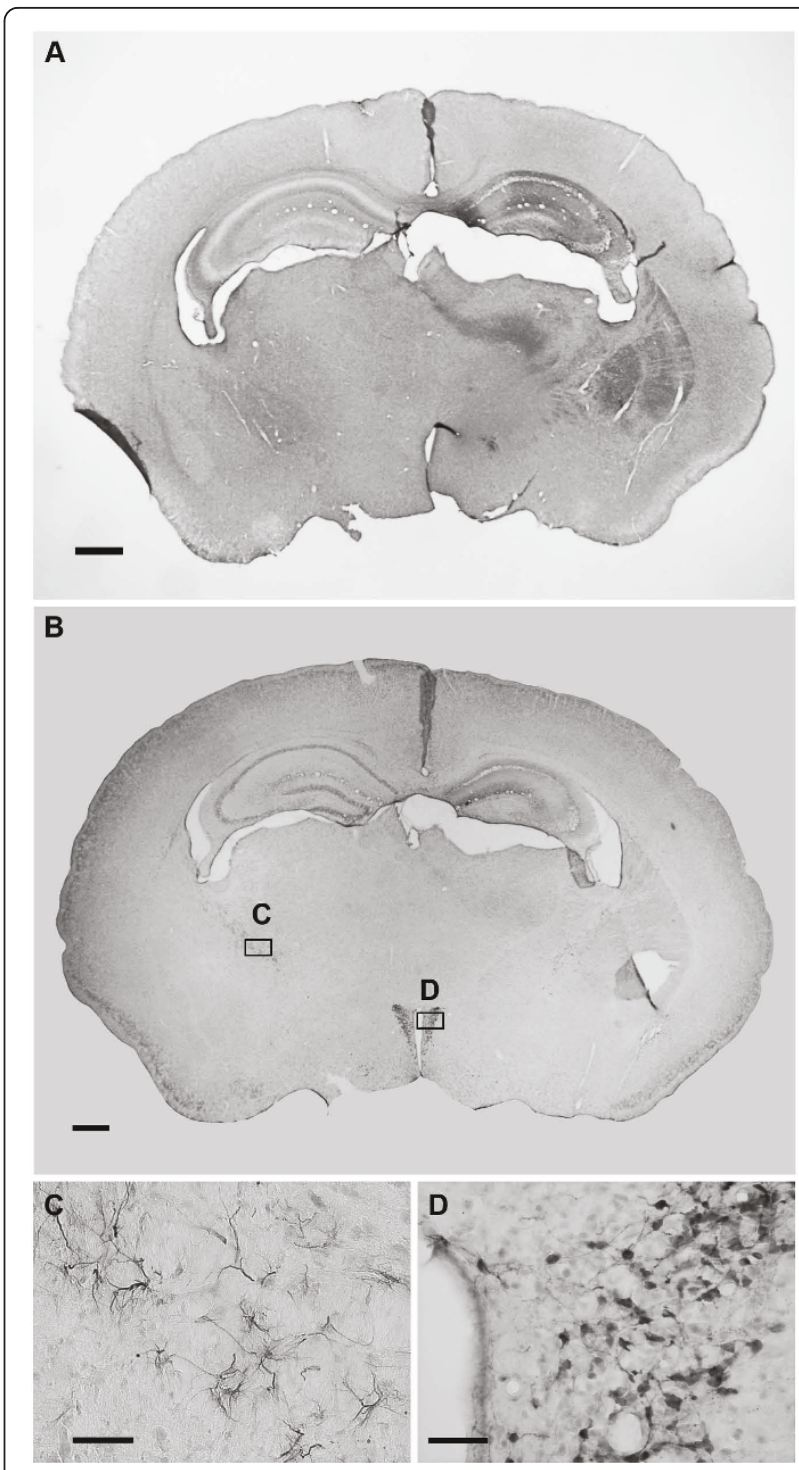

Figure 2 TLR-1 and TLR-2 immunostaining $24 \mathrm{~h}$ after hypoxiaischemia. A: Representative picture of TLR-1 immunostaining $24 \mathrm{~h}$ after hypoxia-ischemia (HI). TLR-1 positive cells were found in the ipsilateral (damaged) side of the brain, primarily in hippocampus, striatum and thalamus. B: Representative picture of TLR-2

immunostaining $24 \mathrm{~h}$ after $\mathrm{HI}$. TLR-2 positive cells were found in white matter e.g. stria terminalis and in the paraventricular nucleus of hypothalamus (PVN). C: High magnification of TLR-2 positive cells in stria terminalis representing the area of the $\mathrm{C}$ box in figure $\mathrm{B}$. D: High magnification of TLR-2 positive cells in the PVN representing the area of the D box in figure B. Scale bars: A-B: $500 \mu \mathrm{m}, \mathrm{C}-\mathrm{D}$ : 50 $\mu \mathrm{m}$

expression for TLR-1, $-2,-5,-7$ and -8 after $\mathrm{HI}$, with the largest up-regulation occurring for TLR-1 and TLR-2. Both TLR-1 and -2 immunoreactivity was also detected in the brain, however, only TLR-2 KO mice were protected from HI injury suggesting that TLR-2 may play an important role in neonatal $\mathrm{HI}$ 

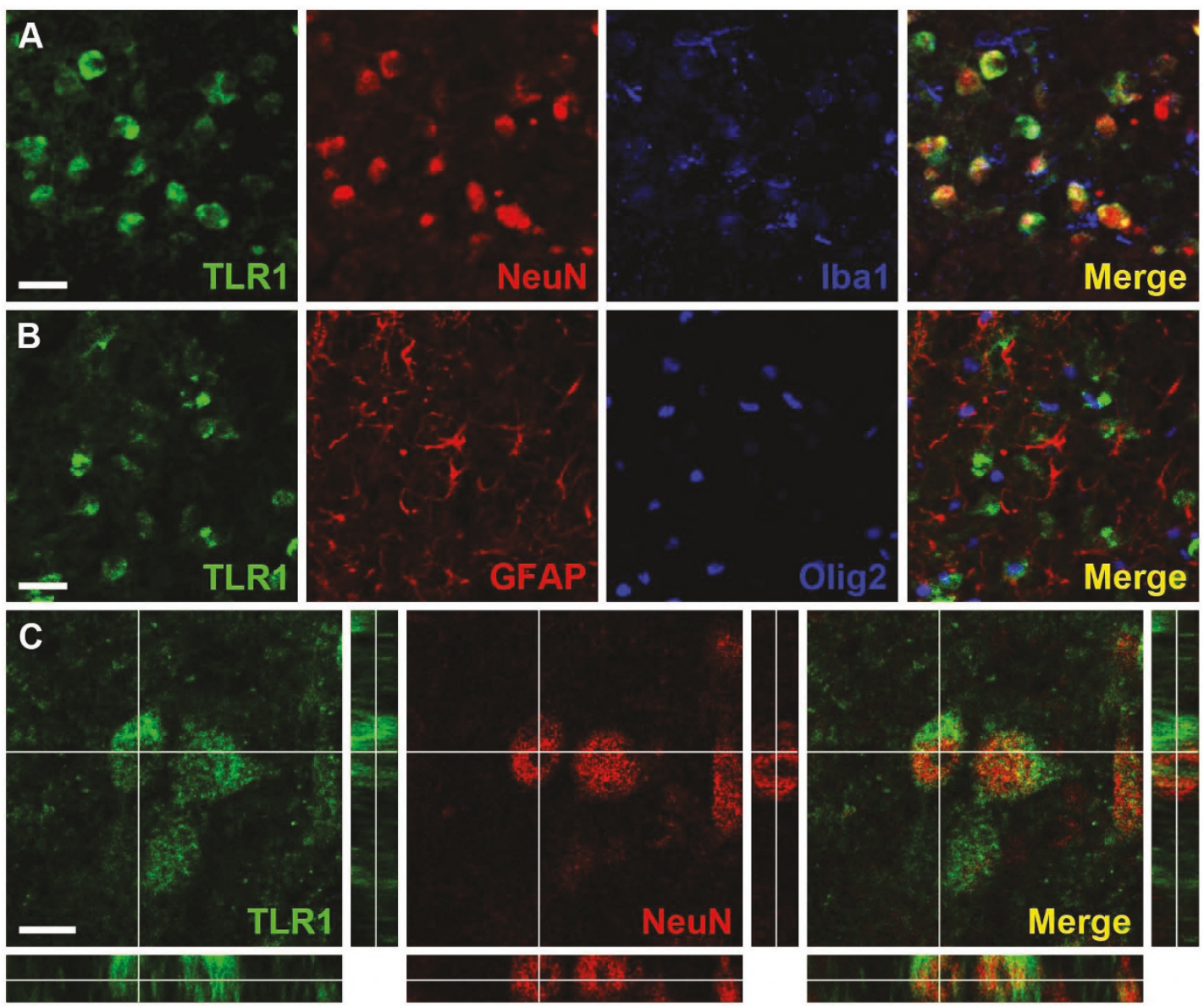

Figure 3 Neurons express TLR-1 24 h after hypoxia-ischemia. A: Triple immunofluorescence staining for TLR-1, NeuN and Iba-1; the merged picture displays expression of TLR-1 by NeuN positive neurons but not lba-1 positive microglia. B: Triple immunofluorescence staining for TLR-1, GFAP and Olig2; The merged picture shows mutually exclusive expression of TLR-1, GFAP Olig2 and no co-localisation of all three markers. C: High magnification orthogonal views of cells stained with TLR-1 and NeuN; the merged picture shows membranous localisation of TLR-1 surrounding NeuN positive nuclei. All images were captured in the ipsilateral hippocampus. Scale bars: A-B: $25 \mu \mathrm{m}$ C: $10 \mu \mathrm{m}$

In the present study we demonstrated the presence of TLR 1-9 mRNA in the normal neonatal brain under physiological conditions. Similarly, studies in human cerebral tissue have indicated that mRNA for most TLRs is expressed in numerous cell types [20]. In vitro studies also indicate a broad expression of TLR mRNA in numerous neural cell types [21,24-26], although the expression of neuronal TLR mRNA is more controversial [27]. Taken together, TLRs are expressed under basal conditions in both the immature and adult brain in numerous cell types and this may again suggest that they play essential roles in neurophysiology and pathology.

We showed that the mRNA expression for TLR-1, -2, $-5,-7$, and -8 was regulated after $\mathrm{HI}$ as shown on PCR array and confirmed by RT PCR. The regulation of TLR genes after neonatal $\mathrm{HI}$ is consistent with several studies in the adult brain. After $1 \mathrm{~h}$ of middle cerebral artery occlusion (MCAO), Lehnardt et al. found up-regulation of TLR-2 mRNA expression and Ziegler et al. found an induction of TLR-2, -4 , and -9 mRNA after focal ischemia in mice $[17,18]$. Also, in a model of spinal cord injury, there was an increased mRNA expression of TLR-1, -2, -4, -5, and -7 [28]. This is to some extent similar to our results indicating an increase of TLR-1, -2 , and -7 after HI. However, in contrast to studies in adult rodents, we found reduced mRNA expression of TLR-5 (24 h after HI) and TLR-8 (30 min after HI). TLR-3, $-4,-6$ and -9 were not significantly changed after neonatal HI, which suggests that the TLR response to cerebral ischemia differs in the adult compared to the developing brain.

We further investigated the protein distribution of the most regulated TLR genes following HI by immunohistochemical analysis. We found an increase of TLR-1, immunoreactivity in the ipsilateral hemisphere after $\mathrm{HI}$, 

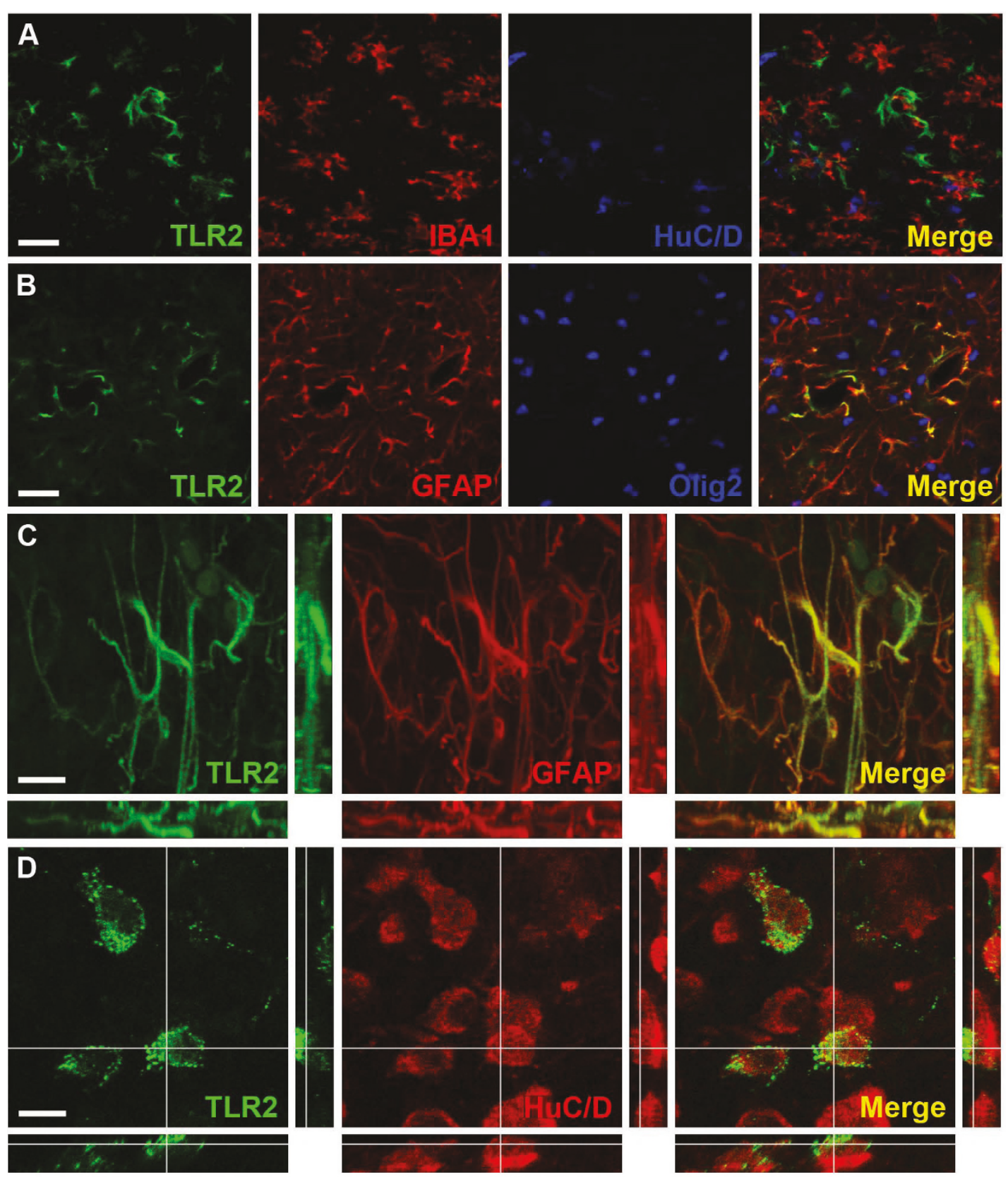

Figure 4 TLR-2 is expressed in astrocytes and neurons. A: Triple immunofluorescence staining for TLR-2, Iba-1 and HuC/D; the merged image indicates mutually exclusive expression of TLR-2, Iba-1 and HuC/D positive cells in the ipsilateral hippocampus. B: Triple immunofluorescence staining for TLR-2, GFAP and Olig2; the merged picture displays apparent co-expression of TLR-2 and GFAP. C: High magnification XYZ, XZ, YZ-average projections of TLR-2 and GFAP co-expressing cells; TLR-2 appears to be associated with cytoskeletal protein GFAP in astrocytes. Pictures A-C were captured in the ipsilateral hippocampus. D: High magnification orthogonal views of TLR-2 and HuC/D double stains in cells in the paraventricular nucleus of the hypothalamus (PVN); the merged picture shows punctate, membranous expression of TLR-2 on HuC/D positive neurons of the PVN. Scale bars: A-B: $25 \mu \mathrm{m}$ C-D: $10 \mu \mathrm{m}$

while TLR-2 was constitutively expressed in the neonatal brain and the expression did not change with HI. Thus, the pattern of protein expression after HI differed to some extent to the mRNA expression. Similarly, Mishra et al. have found differences between mRNA and protein expression and speculate that TLRs can be posttranscriptionally regulated [21].

In the $\mathrm{HI}$ model used in this study, brain injury is predominantly found in the hippocampus, striatum and thalamus [7]. Interestingly, TLR-1 showed increased 


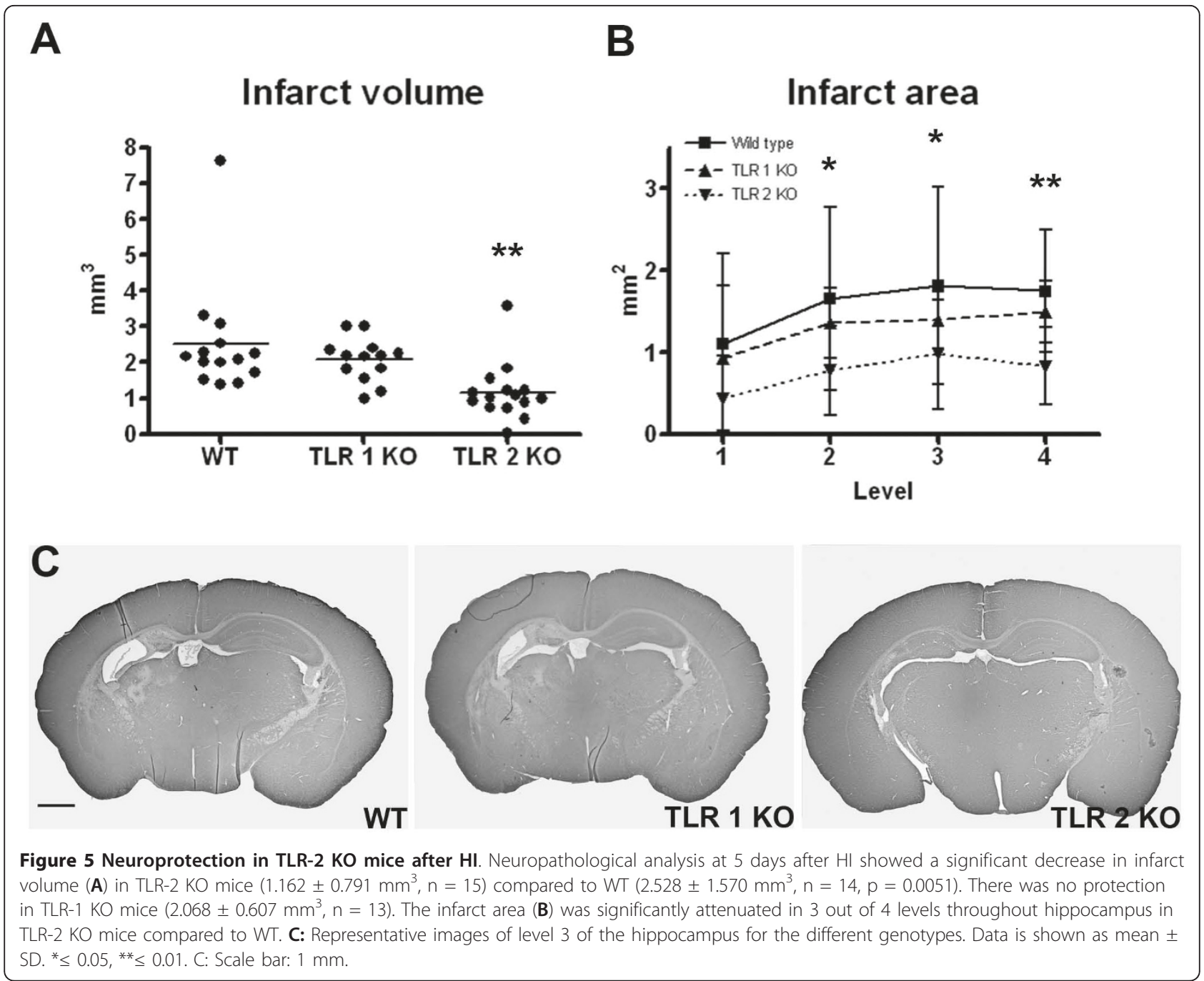

immunoreactivity in neurons, but not other cell types in these brain regions. To our knowledge, there are no previous studies of TLR-1 expression after ischemic injury, either in the adult or developing brain. However, after induction of neurocysticercosis in adult mice, TLR-1 staining was found almost exclusively in infiltrating cells such as microglia/macrophages [21]. These differences in expression may be due to age-and/or injury- dependent factors. Other TLRs have been suggested to have adverse effects on brain development. Deficiency of TLR-3, which is predominantly expressed during embryonic life, increases proliferation of neural progenitor cells [29]. Ma et al. have shown that TLR-8 is expressed on neurons and axons during mouse brain development and that stimulation of this receptor leads to inhibition of neurite outgrowth and induction of apoptosis [30]. Taken together, these studies give support to the hypothesis that activation of certain TLRs can be harmful to the developing brain; however, based on the findings in the present study, the increased expression of TLR-1 in the ischemic brain does not appear to contribute to neonatal damage. In support, we have previously shown that mice deficient in the TLR-1 down-stream adaptor protein MyD88 are not protected from neonatal HI injury [31].

The immunohistochemical expression pattern of TLR2 was different to that of TLR-1, with a constitutive expression both in white matter astrocytes and in a specific population of neurons in PVN. TLR-2 expression has previously been detected in microglia, neurons, ependymal cells and astrocytes, [21] and constitutive expression of TLR-2 has been demonstrated by in situ hybridisation specifically in stria terminalis, PVN, and in the supraoptic nucleus [32]. Thus, our results correspond well with previous reports. Existing studies have shown both a neuroprotective [33] and a damaging $[17,18,26,34]$ role for TLR-2 in the injured brain. It has also been demonstrated that cerebral cortical neurons 
up-regulate TLR-2 in response to ischemia/reperfusion injury and that an increased number of apoptotic neurons are found in the murine dentate gyrus $24 \mathrm{~h}$ after stimulation with a TLR-2 agonist [26,34]. Other studies have found that TLR-2 is involved in adult hippocampal neurogenesis [35] and that after a spinal cord injury, TLR-2 is important for the regulation of inflammation and gliosis as well as the repair and functional recovery [28]. We have recently found that repeated stimulation of the TLR-2 receptor during early neonatal development by administration of the TLR-2 agonist Pam3CSK4 results in brain injury and this effect is blocked in TLR-2 deficient mice [36]. Thus these data in neonatal animals support the findings in the present study where TLR-2 KO animals demonstrated a decrease in infarct volume following HI. These results may seem contradictory to our previous results showing no neuroprotective effect in the TLR-2 adaptor protein MyD88. However, studies in adult animals have also shown a differential effect of MyD88 KO and TLR-2 KO following brain damage [37].

We found a specific population of TLR-2 positive neurons in the PVN. Inflammatory stimuli, such as LPS, are known to activate secretory neurons in PVN, a neuronal subpopulation that is important for homeostatic control [38]. Specifically, TLR-4 and MyD88 have been implicated in circadian responses and anorexia respectively $[39,40]$. The function of the TLR-2 immunoreactive neurons in PVN is unknown but we speculate that they may participate in the neuroendocrine response of the hypothalamus and may act as sensors for incoming inflammatory signals.

\section{Conclusions}

This study demonstrates that a number of TLRs are regulated after $\mathrm{HI}$ in the neonatal brain, both on the mRNA and protein level. TLR-1 protein expression was found to be up-regulated in damaged areas of the brain, however based on the studies in TLR-1 deficient mice, did not appear to be involved in the injurious processes causing ischemic injury. In contrast, TLR-2 protein expression was constitutively expressed and did not change after HI. On the other hand TLR-2 deficiency did protect the immature brain from HI damage, which may indicate that TLR-2 plays a role in neonatal ischemic injury.

\section{Acknowledgements}

This work was supported by grants from the Swedish Research Council (VR 2009-2630, CM; VR K2009-54X-21119-01-4, XW), Åhléns stiftelsen (CM), Frimurare barnhusfonden (CM), Lundgrenska stiftelserna (CM, XW, LS), the European Union (HEALTH-F2-2009-241778, Neurobid, CM), ALFGBG-142881 (CM) and National Natural Science Foundation of China (30973240, XW).

\section{Author details}

${ }^{1}$ Institute of Neuroscience and Physiology, Sahlgrenska Academy, University of Gothenburg, Gothenburg, Sweden. ${ }^{2}$ Center of Brain Research and Rehabilitation, Institute of Neuroscience and Physiology, University of
Gothenburg, Gothenburg, Sweden. ${ }^{3}$ Department of Pediatrics, the Third Affiliated Hospital of Zhengzhou University, 450052 Zhengzhou, China.

\section{Authors' contributions}

CM, LS and XW conceived and designed the study; LS, PS and XW performed and analysed the experiments. LS, CM, PS and AN drafted the manuscript. All authors have read and approved the final version of the manuscript.

\section{Competing interests}

The authors declare that they have no competing interests.

Received: 29 November 2010 Accepted: 10 May 2011

Published: 10 May 2011

\section{References}

1. Fatemi A, Wilson MA, Johnston MV: Hypoxic-ischemic encephalopathy in the term infant. Clin Perinatol 2009, 36:835-858, vii.

2. Dammann O, O'Shea TM: Cytokines and perinatal brain damage. Clin Perinatol 2008, 35:643-663, v.

3. Savman K, Blennow M, Gustafson K, Tarkowski E, Hagberg H: Cytokine response in cerebrospinal fluid after birth asphyxia. Pediatr Res 1998, 43:746-751.

4. Hedtjarn M, Mallard C, Hagberg H: Inflammatory gene profiling in the developing mouse brain after hypoxia-ischemia. J Cereb Blood Flow Metab 2004, 24:1333-1351.

5. Doverhag C, Hedtjarn M, Poirier F, Mallard C, Hagberg H, Karlsson A, Savman K: Galectin-3 contributes to neonatal hypoxic-ischemic brain injury. Neurobiol Dis 2010, 38:36-46.

6. Hedtjarn M, Leverin AL, Eriksson K, Blomgren $\mathrm{K}$, Mallard C, Hagberg H: Interleukin-18 involvement in hypoxic-ischemic brain injury. J Neurosci 2002, 22:5910-5919.

7. Svedin P, Hagberg H, Savman K, Zhu C, Mallard C: Matrix metalloproteinase- 9 gene knock-out protects the immature brain after cerebral hypoxia-ischemia. J Neurosci 2007, 27:1511-1518.

8. Aden U, Favrais G, Plaisant F, Winerdal M, Felderhoff-Mueser U, Lampa J, Lelievre $V$, Gressens P: Systemic inflammation sensitizes the neonatal brain to excitotoxicity through a pro-/anti-inflammatory imbalance: key role of TNFalpha pathway and protection by etanercept. Brain Behav Immun 2010, 24:747-758.

9. Kaisho T, Akira S: Toll-like receptor function and signaling. J Allergy Clin Immunol 2006, 117:979-987, quiz 988.

10. O'Neill LA, Bowie AG: The family of five: TIR-domain-containing adaptors in Toll-like receptor signalling. Nat Rev Immunol 2007, 7:353-364.

11. Uematsu S, Akira S: Toll-like receptors and innate immunity. J Mol Med 2006, 84:712-725.

12. Kariko $\mathrm{K}, \mathrm{Ni} \mathrm{H}$, Capodici J, Lamphier M, Weissman D: mRNA is an endogenous ligand for Toll-like receptor 3. J Biol Chem 2004, 279:12542-12550.

13. Lehnardt S, Schott E, Trimbuch T, Laubisch D, Krueger C, Wulczyn G, Nitsch R, Weber JR: A Vicious Cycle Involving Release of Heat Shock Protein 60 from Injured Cells and Activation of Toll-Like Receptor 4 Mediates Neurodegeneration in the CNS. J Neurosci 2008, 28:2320-2331.

14. Park JS, Svetkauskaite D, He Q Kim J-Y Strassheim D, Ishizaka A, Abraham E. Involvement of Toll-like Receptors 2 and 4 in Cellular Activation by High Mobility Group Box 1 Protein. J Biol Chem 2004, 279:7370-7377.

15. Gao Y, Fang X, Tong Y, Liu Y, Zhang B: TLR4-mediated MyD88-dependent signaling pathway is activated by cerebral ischemia-reperfusion in cortex in mice. Biomed Pharmacother 2008.

16. Cao CX, Yang QW, LV FL, Cui J, Fu HB, Wang JZ: Reduced cerebral ischemia-reperfusion injury in Toll-like receptor 4 deficient mice. Biochem Biophys Res Commun 2007, 353:509-514

17. Lehnardt S, Lehmann S, Kaul D, Tschimmel K, Hoffmann O, Cho S, Krueger C, Nitsch R, Meisel A, Weber JR: Toll-like receptor 2 mediates CNS injury in focal cerebral ischemia. J Neuroimmunol 2007, 190:28-33.

18. Ziegler G, Harhausen D, Schepers C, Hoffmann O, Rohr C, Prinz V, Konig J, Lehrach H, Nietfeld W, Trendelenburg G: TLR2 has a detrimental role in mouse transient focal cerebral ischemia. Biochem Biophys Res Commun 2007, 359:574-579

19. Caso JR, Pradillo JM, Hurtado O, Lorenzo P, Moro MA, Lizasoain I: Toll-Like Receptor 4 Is Involved in Brain Damage and Inflammation After Experimental Stroke. Circulation 2007, 115:1599-1608. 
20. Bsibsi M, Ravid R, Gveric D, van Noort JM: Broad expression of Toll-like receptors in the human central nervous system. J Neuropathol Exp Neurol 2002, 61:1013-1021.

21. Mishra BB, Mishra PK, Teale JM: Expression and distribution of Toll like receptors in the brain during murine neurocysticercosis. J Neuroimmunol 2006, 181:46-56.

22. Rice JE, Vannucci RC, Brierley JB: The influence of immaturity on hypoxicischemic brain damage in the rat. Ann Neurol 1981, 9:131-141.

23. Blomgren $\mathrm{K}$, Hallin U, Andersson AL, Puka-Sundvall M, Bahr BA, McRae A, Saido TC, Kawashima S, Hagberg H: Calpastatin is up-regulated in response to hypoxia and is a suicide substrate to calpain after neonatal cerebral hypoxia-ischemia. J Biol Chem 1999, 274:14046-14052.

24. Jack CS, Arbour N, Manusow J, Montgrain V, Blain M, McCrea E, Shapiro A, Antel JP: TLR Signaling Tailors Innate Immune Responses in Human Microglia and Astrocytes. J Immunol 2005, 175:4320-4330.

25. Olson JK, Miller SD: Microglia Initiate Central Nervous System Innate and Adaptive Immune Responses through Multiple TLRs. J Immunol 2004, 173:3916-3924.

26. Tang SC, Arumugam TV, Xu X, Cheng A, Mughal MR, Jo DG, Lathia JD, Siler DA, Chigurupati S, Ouyang $X$, et al: Pivotal role for neuronal Toll-like receptors in ischemic brain injury and functional deficits. Proc Natl Acad Sci USA 2007, 104:13798-13803.

27. Chakravarty S, Herkenham M: Toll-like receptor 4 on nonhematopoietic cells sustains CNS inflammation during endotoxemia, independent of systemic cytokines. J Neurosci 2005, 25:1788-1796.

28. Kigerl KA, Lai W, Rivest S, Hart RP, Satoskar AR, Popovich PG: Toll-like receptor (TLR)-2 and TLR-4 regulate inflammation, gliosis, and myelin sparing after spinal cord injury. J Neurochem 2007, 102:37-50.

29. Cameron JS, Alexopoulou L, Sloane JA, DiBernardo AB, Ma Y, Kosaras B, Flavell R, Strittmatter SM, Volpe J, Sidman R, Vartanian T: Toll-like receptor 3 is a potent negative regulator of axonal growth in mammals. J Neurosci 2007, 27:13033-13041.

30. Ma Y, Li J, Chiu I, Wang Y, Sloane JA, Lu J, Kosaras B, Sidman RL, Volpe JJ, Vartanian T: Toll-like receptor 8 functions as a negative regulator of neurite outgrowth and inducer of neuronal apoptosis. J Cell Biol 2006, 175:209-215.

31. Mallard C, Wang $X$, Hagberg $H$ : The role of Toll-like receptors in perinatal brain injury. Clin Perinatol 2009, 36:763-772, v-vi.

32. Laflamme N, Soucy G, Rivest S: Circulating cell wall components derived from gram-negative, not gram-positive, bacteria cause a profound induction of the gene-encoding Toll-like receptor 2 in the CNS. J Neurochem 2001, 79:648-657.

33. Hua F, Ma J, Ha T, Kelley JL, Kao RL, Schweitzer JB, Kalbfleisch JH, Williams DL, Li C: Differential roles of TLR2 and TLR4 in acute focal cerebral ischemia/reperfusion injury in mice. Brain Res 2009, 1262:100-108.

34. Hoffmann O, Braun JS, Becker D, Halle A, Freyer D, Dagand E, Lehnardt S, Weber JR: TLR2 mediates neuroinflammation and neuronal damage. J Immunol 2007, 178:6476-6481.

35. Rolls A, Shechter R, London A, Ziv Y, Ronen A, Levy R, Schwartz M: Toll-like receptors modulate adult hippocampal neurogenesis. Nat Cell Biol 2007, 9:1081-1088.

36. Du X, Fleiss B, Li H, D'angelo B, Sun Y, Zhu C, Hagberg H, Levy O, Mallard C, Wang $X$ : Systemic stimulation of TLR2 impairs neonatal mouse brain development. PloS one 2011

37. Koedel U, Merbt UM, Schmidt C, Angele B, Popp B, Wagner H, Pfister H-W Kirschning CJ: Acute Brain Injury Triggers MyD88-Dependent, TLR2/4Independent Inflammatory Responses. Am J Pathol 2007, 171:200-213.

38. Loum-Ribot E, Lafon P, Chaigniau M, Pape JR, Tramu G, Corio M: Paraventricular nucleus neurons producing neurotensin after lipopolysaccharide treatment project to the median eminence. Brain Res 2004, 1030:294-296.

39. Paladino N, Leone MJ, Plano SA, Golombek DA: Paying the circadian toll: The circadian response to LPS injection is dependent on the Toll-like receptor 4. J Neuroimmunol 2010, 225:62-67.

40. Yamawaki Y, Kimura H, Hosoi T, Ozawa K: MyD88 plays a key role in LPSinduced Stat3 activation in the hypothalamus. Am J Physiol Regul Integr Comp Physiol 2010, 298:R403-410. doi:10.1186/1742-2094-8-45

Cite this article as: Stridh et al:: Regulation of Toll-like receptor 1 and -2 in neonatal mice brains after hypoxia-ischemia. Journal of Neuroinflammation 2011 8:45.

\section{Submit your next manuscript to BioMed Central and take full advantage of:}

- Convenient online submission

- Thorough peer review

- No space constraints or color figure charges

- Immediate publication on acceptance

- Inclusion in PubMed, CAS, Scopus and Google Scholar

- Research which is freely available for redistribution

Submit your manuscript at www.biomedcentral.com/submit
C) Biomed Central 